\title{
Protrusio Acetabuli
}

\section{New Insights and Experience with Joint Preservation}

\author{
Michael Leunig MD, Shane J. Nho MD, MS, \\ Luigino Turchetto MD, Reinhold Ganz MD
}

Published online: 1 May 2009

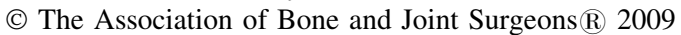

\begin{abstract}
Protrusio acetabuli is identified on anteroposterior (AP) radiographs of the pelvis with an acetabular line projecting medial to the ilioischial line. We documented this radiographic sign and additional radiographic parameters in 19 patients (29 hips) with protrusio and compared the parameters to those of 29 older patients ( $29 \mathrm{hips}$ ) with advanced primary osteoarthritis (OA) but no protrusio and 12 younger patients (22 hips) with protrusio but no advanced OA. A negative acetabular roof angle and particularly large acetabular fossa were more apparent in younger patients; these hips suggest the destruction of a protrusio hip begins less in the medial joint area and more in the posteroinferior joint, and the mechanism is driven less by excessive medially directed forces but by a pincer
\end{abstract}

Each author certifies that he or she has no commercial associations (eg, consultancies, stock ownership, equity interest, patent/licensing arrangements, etc) that might pose a conflict of interest in connection with the submitted article.

Each author certifies that his institution either has waived or does not require approval for the human protocol for this investigation and that all investigations were conducted in conformity with ethical principles of research.

M. Leunig, S. J. Nho

Hip Service, Schulthess Clinic, Zurich, Switzerland

S. J. Nho $(\bowtie)$

Rush University Medical Center, 1725 West Harrison Street,

Suite 1063, Chicago, IL, USA

e-mail: snho@hotmail.com

L. Turchetto

Orthopaedic Department, Veneto Regional Hospital,

Portogruaro, Italy

R. Ganz

Orthopaedic Department, University of Berne, Berne,

Switzerland impingement. While the indication for joint-preserving surgery currently consists primarily of a valgus femoral osteotomy based on AP radiographs and patient age, modern decision making also relies on cartilage evaluation and requires advanced surgical techniques. We conclude joint-preservation surgery must be tailored to the individual hip morphology.

Level of Evidence: Level III, prognostic study. See Guidelines for Authors for a complete description of levels of evidence.

\section{Introduction}

The pathomorphology of an acetabulum protruding into the true pelvis was first described by Otto in 1816 [20]. During the next 100 years, the interest in hip protrusion was focused on etiology and classification, while treatment recommendations remained limited. In 1935, Overgaard [21] presented the first useful classification into primary and secondary protrusio, which was later modified by Gilmour [12] into the most commonly used classification today. It distinguishes between cases explained by an underlying disease (secondary) and those without such etiological explanation (primary). Today, the list of causes of secondary protrusion ranges widely from infection, trauma, and underlying metabolic, neoplastic, and genetic diseases [7]. Bilateral manifestation with a female predominance has typically been described for primary protrusio [1, 12]. Heredity [6] and racial influence [4] have also been reported. A number of morphological arguments including accelerated epiphyseal growth and premature fusion of the triradiate cartilage have suggested a developmental etiology [7] of primary protrusion; however, these have not yet been substantiated. 
The consequence of acetabular protrusio is secondary osteoarthritis (OA) and has been characterized by a loss of medial joint space, while the craniolateral (superior) joint space initially remains largely unaltered. The mechanism has been explained by higher load transmission through the medial aspect of the joint $[5,18]$. Even in minimal primary protrusion the femoral head has been observed to migrate medially over time. We presume the acetabular morphology of the protrusion with OA differs from the classic OA patients.

The present standard surgical treatment in middle and older age has been total joint replacement, while resection arthroplasty and even arthrodesis were historical treatment options. Anterior acetabuloplasty was first performed by Smith-Petersen [28] to increase motion in older patients with marked stiffness. Surgical closure of the triradiate cartilage has been proposed for the skeletally immature hip [29]; however, this approach has not been widely adopted, in part because of the inability to predict which hips will undergo progressive protrusion. Valgus intertrochanteric osteotomy has also been recommended in the young adult under the age of 40 years without the presence of arthritic changes [7, 19, 24].

The aims of this paper were: (1) to compare the morphology using preoperative radiographs in an arthroplasty database of a cohort of patients with acetabular protrusion with osteoarthritis to an age- and gender-matched cohort with classic osteoarthritis; (2) to characterize the morphology of young patients with acetabular protrusion and to compare these patients to the patients with acetabular protrusion with osteoarthritis; and (3) to retrospectively review the clinical and radiographic information of the young protrusion patients who underwent joint-preserving surgery.

\section{Material and Methods}

We retrospectively compared the radiographic parameters in 19 patients (29 hips) with acetabular protrusio who underwent total hip replacement for secondary OA (protrusio OA group) to those in two groups of patients: (1) 29 patients (29 hips) with OA (but no protrusio) who were age-, gender-, and Tönnis scale [30] matched (OA Control group), and (2) 12 young ( $<43$ years of age) patients $(22$ hips) with protrusio being evaluated for possible jointpreserving surgery (protrusio joint preservation group). The 19 patients with protrusio included all those patients between 35 and 81 years who had undergone total hip arthroplasty. Protrusio was defined by an acetabular line crossing the ilioischial line by $3 \mathrm{~mm}$ (male) or $6 \mathrm{~mm}$ (female) on the anteroposterior (AP) view (Fig. 1A-C) $[2,13,31]$.

The patient demographic information was recorded including the age, gender, hip involvement (unilateral or bilateral), type (primary or alternate diagnosis), and subsequent surgical procedures.

All patients of both groups had a standard AP radiograph of the pelvis with the patient in a supine position and cross-table lateral views. All radiographs were performed with the coccyx positioned in the midline, about $1 \mathrm{~cm}$ above the pubic symphysis (neutral tilt) and the obturator

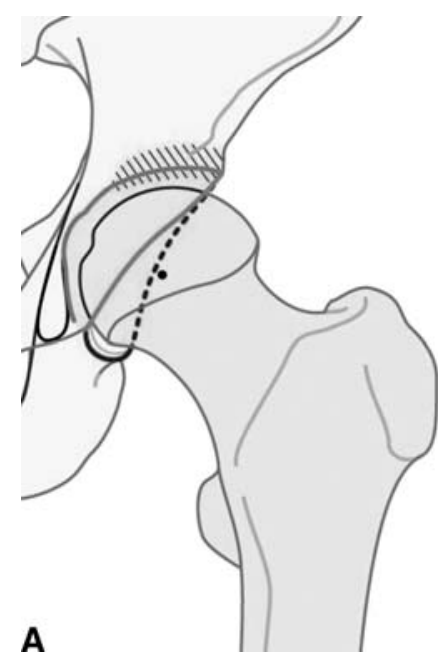

B

Fig. 1 (A) In a normal hip, the acetabulum sufficiently covers the femoral head. (B) In coxa profunda, the head is more medial with the acetabular fossa being at or medial to the ilioischial line. (C) In protrusio, the femoral head is close, at or medial to the ilioischial line and the acetabular roof is negatively tilted with the center of the femoral head

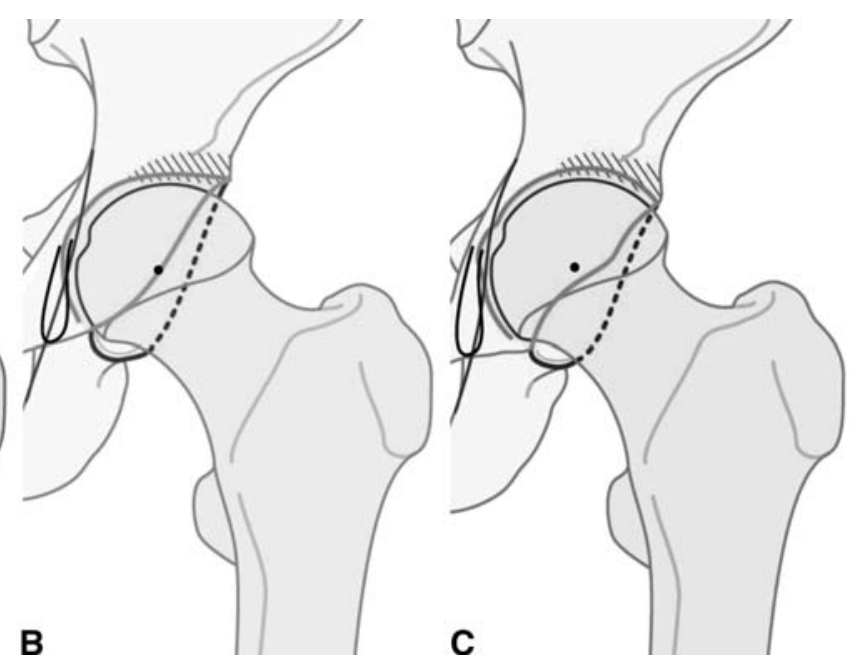

being medial to the anterior and posterior acetabular walls. (Reprinted with permission from Leunig, M., Huff, T., Ganz, R. Femoroacetabular impingement: Treatment of the acetabular side. In: Azar FM, O'Connor MI (eds). Instructional Course Lectures 58. Rosemont, IL: American Academy of Orthopaedic Surgeons; 2009:223-229.) 
foramina and the greater trochanter symmetrical (neutral rotation) [26]. All radiographs were graded using tools to measure length $(\mathrm{mm})$ and angles $\left(^{\circ}\right)$ provided by the PACS by one orthopaedic surgeon (SJN). The joint space was measured at two points, medial and superior. The following parameters were measured: Tönnis angle [30], Sharp's angle [25], the lateral center edge (LCE) angle of Wiberg [32], femoral head extrusion index, neck-shaft angle, crossover sign, posterior wall sign [23], ilioischial line relative to acetabular fossa, center of rotation of femoral head relative to the top of the trochanter [32].

According to availability, additional information from the radiographic studies was also recorded including false profile radiographs [15], computer tomography, and magnetic resonance (MR) arthrography [17]. These studies have been used to determine whether pathomorphological aspects can be better visualized than with AP pelvic radiographs alone and have currently been used to guide treatment for joint-preservation surgery [19, 21, 22]. Furthermore, the radiographic findings of previously operated hips from this group have been correlated to the intraoperative pathology observed during routine surgical hip dislocation [9]. False profile views to show the posteroinferior joint space [15] were available from seven hips. Computer tomography was performed in four patients and MR arthrography was available from seven hips.

At the time of surgery, the amount and location of cartilage injury was recorded. Except for one hip with reversed periacetabular osteotomy only, the first step of surgery was surgical dislocation [9], followed by global or localized trimming of the acetabular rim, and/or relative neck lengthening [10], and/or reversed periacetabular osteotomy (PAO) [27] and/or valgus intertrochanteric osteotomy. In a reversed PAO, the protrusio acetabulum was reoriented with flexion and internal rotation of the acetabular fragment to allow impingment-free motion in flexion and internal rotation.

Histograms were performed to determine whether the data were normally distributed. Superior joint space and the medial joint space measurements were the only measurements that did not follow a normal distribution and for these we used nonparametric tests. We determined differences in superior joint space and medial joint space between all groups using the Kruskal-Wallis tests and performed post-hoc analysis with Tukey test to compare between protrusio OA and control OA cohorts and between protrusio $\mathrm{OA}$ and protrusio joint preservation cohorts. We determined differences in radiographic morphology (Tönnis angle, Sharp's angle, LCE angle, FH extrusion, neck-shaft angle) between protrusio OA and control OA cohorts using one-way ANOVA with Bonferroni post-hoc analysis. We also determined differences in radiographic morphology (Tönnis angle, Sharp's angle, LCE angle, FH extrusion, neck-shaft angle) between protrusio OA and protrusio joint preservation cohorts using one-way ANOVA with Bonferroni post-hoc analysis. Analysis was performed using SPSS software (SPSS, Inc., Chicago, IL).

\section{Results}

We observed a number of radiographic differences between protrusion hips and the OA control group. Although the degree of joint degeneration was similar between the two cohorts (Table 1), the pattern of joint space narrowing differed markedly (Tables 2,3 ). In the protrusio group, the medial joint space was decreased and the superior joint space was increased when compared to the OA control group. The acetabular morphology also differed between the two groups. All hips in the protrusio group had an ilioischial line lateral to the acetabular fossa, whereas the opposite was observed in the hips of the OA control group. The posterior rim was lateral to the center of rotation in a greater percentage $(\mathrm{p}=0.004)$ of the hips in

Table 1. Matched group characteristics

\begin{tabular}{llll}
\hline Variables & $\begin{array}{l}\text { Osteoarthritis } \\
\text { protrusion }(\%)\end{array}$ & $\begin{array}{l}\text { Protrusion joint } \\
\text { preservation }(\%)\end{array}$ & $\begin{array}{l}\text { Osteoarthritis } \\
\text { control }(\%)\end{array}$ \\
\hline $\begin{array}{l}\text { No. Patients } \\
\text { No. Hips }\end{array}$ & 19 & 12 & 29 \\
Gender & 29 & 12 & 29 \\
$\quad$ Male & $2(11)$ & $2(17)$ & $6(21)$ \\
$\quad$ Female & $17(89)$ & $10(83)$ & $23(79)$ \\
Tonnis Scale & & & \\
$\quad$ Grade 0 & $0(0)$ & $3(25)$ & $0(0)$ \\
$\quad$ Grade 1 & $9(31)$ & $8(67)$ & $8(28)$ \\
$\quad$ Grade 2 & $8(28)$ & $1(8)$ & $11(38)$ \\
Grade 3 & $12(41)$ & $0(0)$ & $10(34)$ \\
\hline
\end{tabular}

Table 2. Radiographic measurements of protrusio acetabuli with osteoarthritis compared to osteoarthritis control patients

\begin{tabular}{lccc}
\hline Variable & $\begin{array}{l}\text { Osteoarthritis } \\
\text { protrusion } \\
\text { Mean } \pm \text { SD }\end{array}$ & $\begin{array}{l}\text { Osteoarthritis } \\
\text { control } \\
\text { Mean } \pm \text { SD }\end{array}$ & P Value \\
\hline Age & $66 \pm 14$ & $67 \pm 12$ & 0.9923 \\
Superior joint space $(\mathrm{mm})$ & $4 \pm 1$ & $1 \pm 1$ & 0.0001 \\
Medial joint space $(\mathrm{mm})$ & $3 \pm 1$ & $3 \pm 2$ & 0.2590 \\
Tonnis angle $\left(^{\circ}\right)$ & $-14 \pm 9$ & $2 \pm 6$ & 0.0001 \\
Sharp's angle $\left(^{\circ}\right)$ & $51 \pm 10$ & $53 \pm 6$ & 0.0140 \\
LCE angle $\left(^{\circ}\right)$ & $60 \pm 8$ & $36 \pm 9$ & 0.0001 \\
FH extrusion index $(\%)$ & $106 \pm 13$ & $68 \pm 18$ & 0.0001 \\
Neck shaft angle & $121 \pm 5$ & $130 \pm 7$ & 0.0001 \\
\hline
\end{tabular}


Table 3. Radiographic measurements of protrusio acetabuli with osteoarthritis compared to protrusio joint preservation patients

\begin{tabular}{lccc}
\hline Variable & $\begin{array}{l}\text { Osteoarthritis } \\
\text { protrusion } \\
\text { Mean } \pm \text { SD }\end{array}$ & $\begin{array}{l}\text { Protrusion } \\
\text { joint preservation } \\
\text { Mean } \pm \text { SD }\end{array}$ & P Value \\
\hline Age & $66 \pm 14$ & $27 \pm 6$ & 0.0001 \\
$\begin{array}{l}\text { Superior joint } \\
\quad \text { space (mm) }\end{array}$ & $4 \pm 1$ & $5 \pm 1$ & 0.0650 \\
Medial joint & $3 \pm 1$ & $2 \pm 1$ & 0.2844 \\
$\quad$ space (mm) & & & \\
Tonnis angle $\left(^{\circ}\right)$ & $-14 \pm 9$ & $-10 \pm 7$ & 0.3510 \\
Sharp's angle $\left(^{\circ}\right)$ & $51 \pm 10$ & $58 \pm 6$ & 0.0160 \\
LCE angle $\left(^{\circ}\right)$ & $60 \pm 8$ & $48 \pm 7$ & 0.0001 \\
FH extrusion index $(\%)$ & $106 \pm 13$ & $111 \pm 8$ & 0.8730 \\
Neck shaft angle & $121 \pm 5$ & $130 \pm 8$ & 0.0001 \\
\hline
\end{tabular}

Table 4. Radiographic evaluation of groups

\begin{tabular}{lclc}
\hline Variables & $\begin{array}{l}\text { Osteoarthritis } \\
\text { protrusion }(\%)\end{array}$ & $\begin{array}{l}\text { Protrusion joint } \\
\text { preservation }(\%)\end{array}$ & $\begin{array}{l}\text { Osteoarthritis } \\
\text { control }(\%)\end{array}$ \\
\hline Cross-over sign & & & \\
No & $29(100)$ & $12(100)$ & $28(97)$ \\
Yes & $0(0)$ & $0(0)$ & $1(3)$ \\
Posterior wall sign & & $22(76)$ \\
No (medial) & $0(0)$ & $0(0)$ & $7(24)$ \\
Yes (lateral) & $29(100)$ & $12(100)$ & $0(0)$ \\
Ilioischial line relative to acetabular fossa & $0(0)$ \\
Lateral & $29(100)$ & $12(100)$ & $29(100)$ \\
Touching & $0(0)$ & $0(0)$ & $9(31)$ \\
Medial & $0(0)$ & $0(0)$ & $19(69)$ \\
COR relative to trochanter & & \\
Varus & $27(93)$ & $11(92)$ & \\
Valgus & $2(7)$ & $1(8)$ & \\
\hline
\end{tabular}

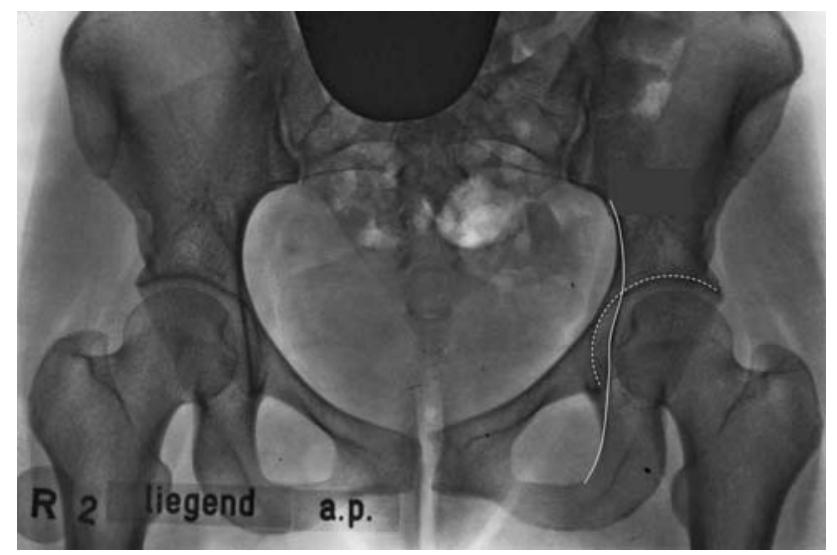

Fig. 2 A 23-year old female patient with bilateral protrusio acetabuli had severe bilateral hip pain and globally restricted ROM since childhood. Protrusio acetabulum with acetabular line (dashed line) crossing the ilioischial line (solid line) by $6 \mathrm{~mm}$ in females and $3 \mathrm{~mm}$ in males. the protrusion group than in the OA control group (100\% versus $24 \%$, respectively). There was only one hip in the OA control group with a positive crossover sign. Parameters that measure lateral coverage, center edge angle, and Sharp's angle were greater in the protrusion group compared to the OA control group. The mean Tönnis angle in the protrusion group differed $(\mathrm{p}=0.0001)$ from that in the OA control group and was negative $\left(-14^{\circ}\right)$ compared to $\left(+2^{\circ}\right)$ in the OA control group. On the femoral side, there were distinguishing radiographic characteristics between the two groups. The center of rotation of the femoral head was lower than the tip of the greater trochanter in $93 \%$ of cases in the protrusion group. The OA control group, in
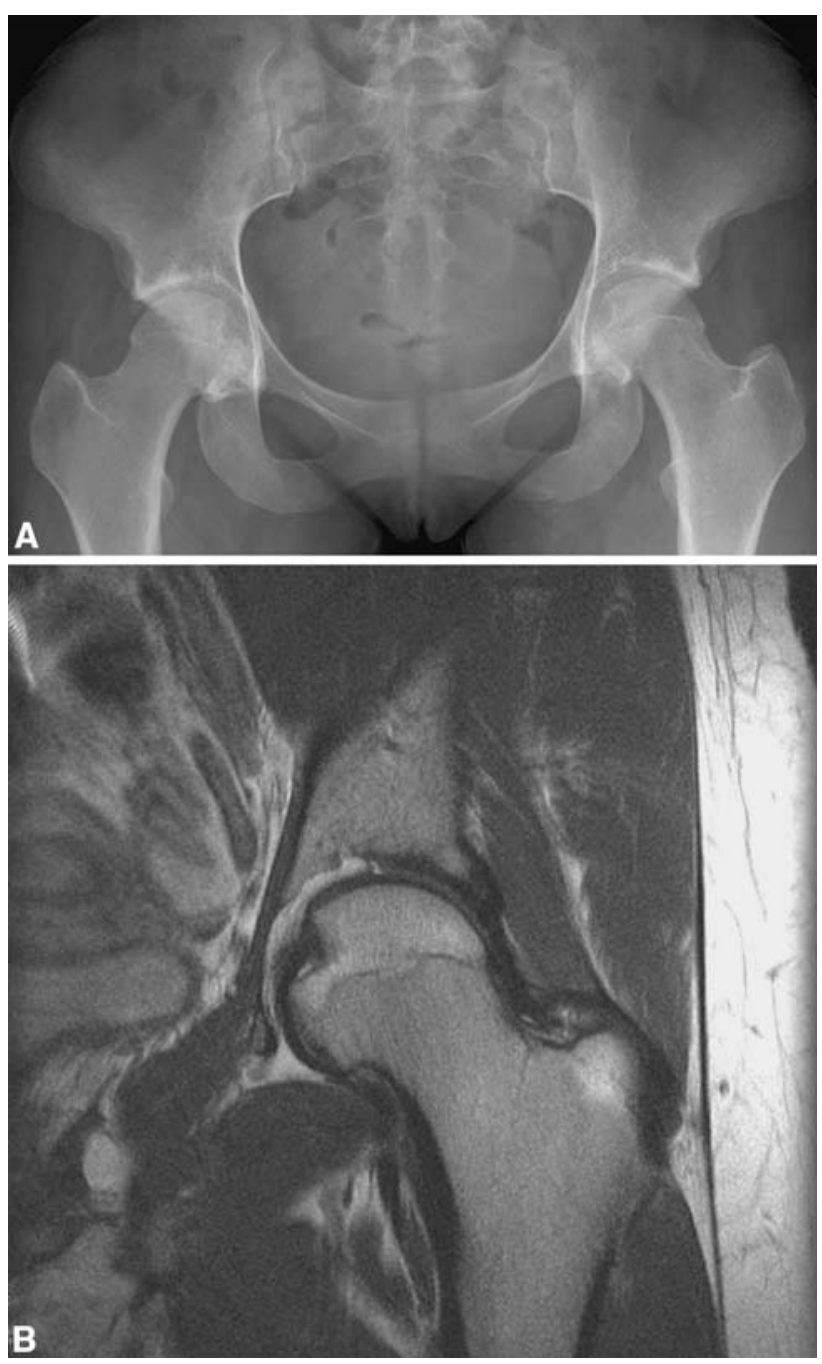

Fig. 3A-B (A) A 22-year old female patient with bilateral borderline protrusio with severe negative inclination of the acetabular roof complained of global limitations in ROM and bilateral hip pain (left worse than right). (B) Coronal cut of an MR arthrography demonstrates that the acetabular fossa extends far into the weight-bearing zone of the roof, and therefore, rim trimming in such a morphological constellation would further reduce the cartilaginous weight-bearing zone to a critical range. 
contrast, had a center of rotation of the femoral head lower than the tip of the trochanter in $69 \%$ of the hips. The neckshaft angle of the protrusio group $\left(121^{\circ}\right)$ was substantially less than the $\mathrm{OA}$ control group $\left(130^{\circ}\right)$.

The radiographic characteristics in the group of young patients differed slightly from those with protrusion and advanced OA (Table 4). However, four hips in two young patients had a substantially negative roof angle, which we interpreted as primary and not due to bone apposition of the rim (Figs. 2, 3A-B).

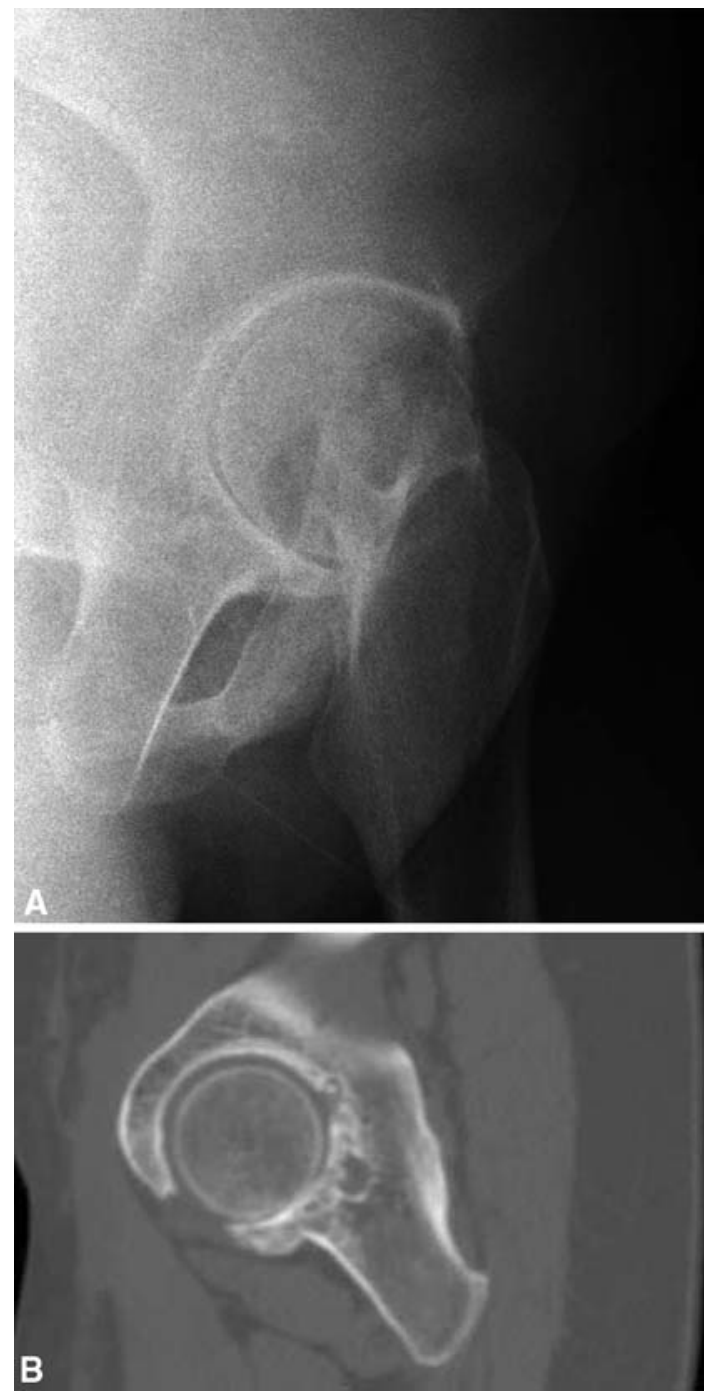

Fig. 4A-B (A) The false profile view of the left hip of a 37-year old female patient with bilateral protrusion who complained of worsening symptoms and loss of extension on the left side is shown. While the superior joint space is preserved, there is marked joint space narrowing in the posteroinferior aspect of the joint. A prominent ossification of the inferior rim is visible, indicating posteroinferior impingement. (B) Computer tomography revealed that the area of cartilage destruction and subchondral cyst formation in the posteroinferior joint is even more extensive than on the false profile view. A large bone apposition of the inferior rim can be seen, explaining the impingement and loss of extension.
Although the superior joint space on the false profile views was still normal with little osteophytic reaction, the posteroinferior joint space was clearly narrowed in four hips (Fig. 4A), an argument against joint-preserving surgery. Computer tomography in the four patients confirmed the findings of the false profile radiography (Fig. 4B). MR arthrography showed cartilage narrowing in the posteroinferior joint from minimal to substantial in all seven hips. In addition, the acetabular fossa subjectively seemed larger than normal in all cases, extending high over the fovea capitis into the weight-bearing zone and resulting in a rather narrow cartilaginous roof in the four hips with marked negative roof angle (Fig. 3B). All seven hips had the typical MR-signs of pincer impingement with bone apposition at the acetabular rim and the femoral neck in various degrees. In one hip we observed considerable cartilage destruction seen on MR posteriorly but also anterosuperiorly.

In all 11 hips having surgical dislocation, cartilage damage from minimal to substantial could be seen at the posteroinferior acetabulum and/or posterior contour of the femoral head (Fig. 5), while the cartilage damage of the medial contour of the head was less severe. We recorded the short-term results of this individualized surgical approach (Table 5).

Because each case is unique, we selected case examples to illustrate the clinical presentation and subsequent surgical procedure. A 24-year old female patient had symptomatic post-traumatic protrusio acetabuli after nonoperative treatment of a complex acetabular fracture (Fig. 6A). We used an ilioinguinal approach to periacetabular osteotomy that allowed manipulation of the acetabular fragment such that the acetabulum was

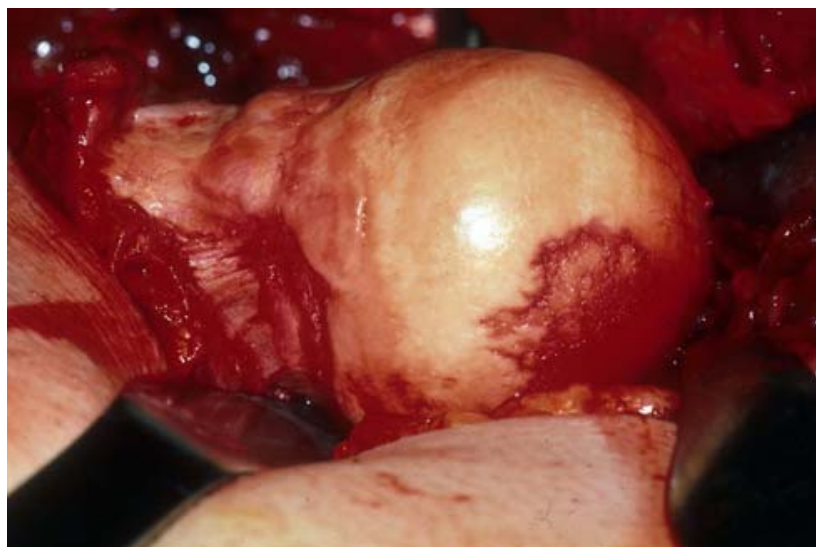

Fig. 5 An intraoperative image of a surgically dislocated femoral head of a protrusion hip shows severe cartilage abrasions of the posterior contour of the head with a corresponding acetabular cartilage lesion (not shown). With head relocation, the impingement mechanism can be reproduced, and the mode of origin of the "contre coup lesion" [30] can be observed. 


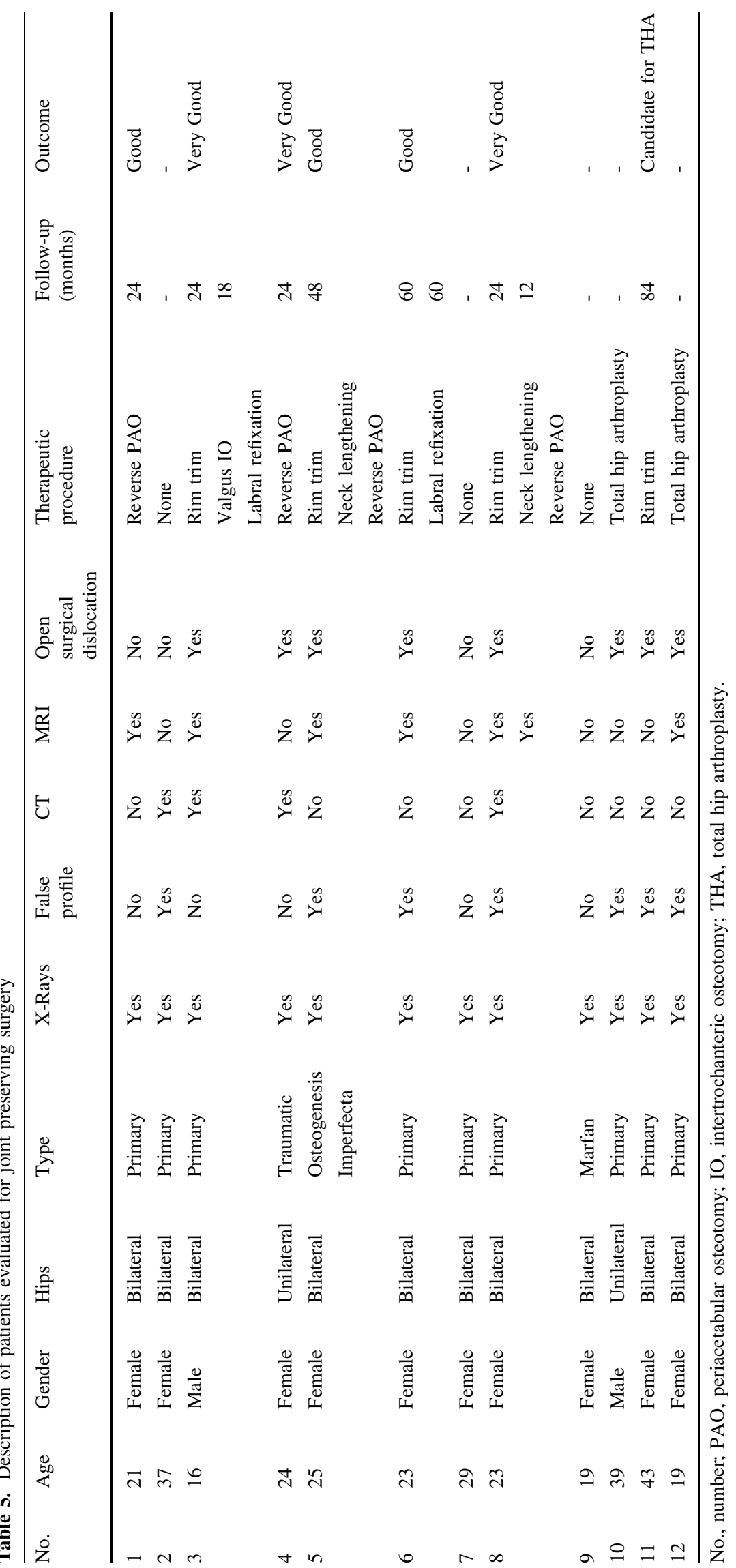



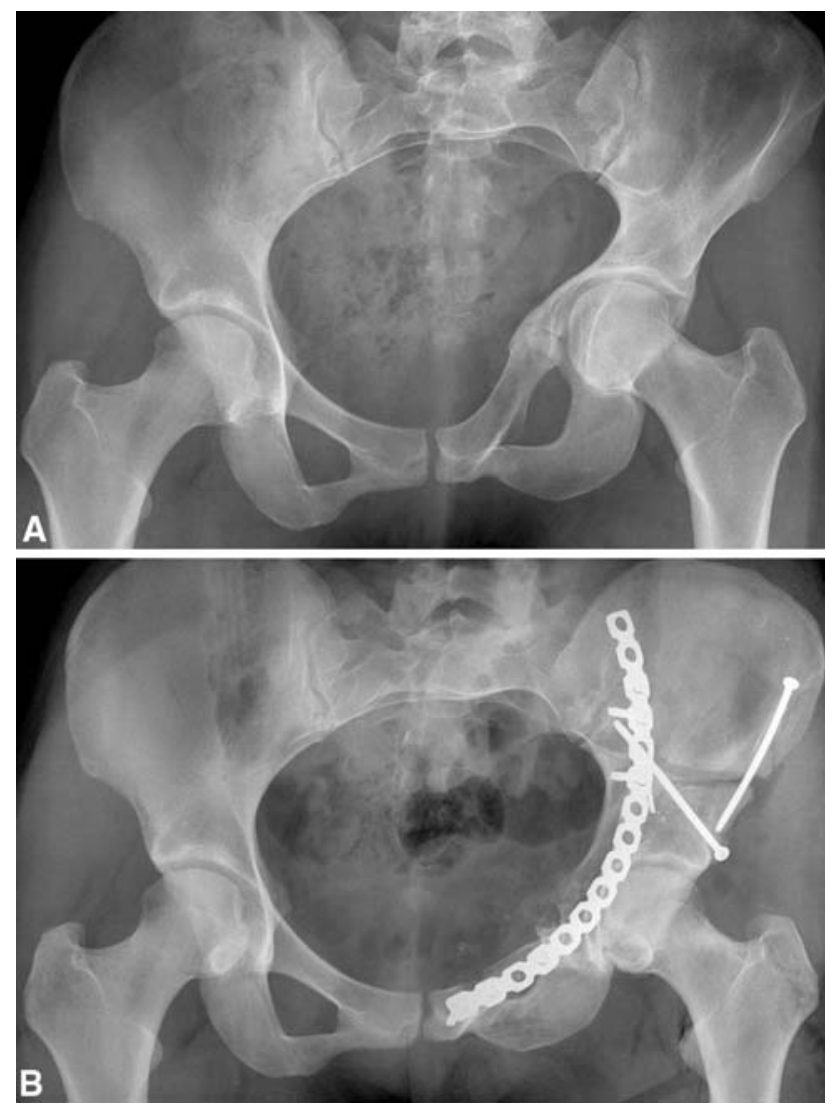

Fig. 6A-B (A) Shown is a 24-year old female patient with posttraumatic protrusio acetabuli after nonoperative treatment of a complex acetabular fracture. (B) An ilioinguinal approach was utilized, and the periacetabular osteotomy allowed manipulation of the acetabular fragment such that the acetabulum was lateralized with anatomic correction of the pubic ramus with a 16-hole pelvic reconstruction plate.

lateralized with anatomic correction of the pubic ramus with a 16-hole pelvic reconstruction plate (Fig. 6B). Less than a year after surgery, the patient had a successful vaginal delivery. One 25-year old female had osteogenesis imperfecta with limited ROM until a fatigue fracture of the acetabular fossa (Fig. 7A). We originally planned a surgical dislocation with circumferential rim trimming and relative lengthening of the femoral neck. MR arthrography revealed mild cartilage injury around the medial contour of the head. Therefore we performed a reversed periacetabular osteotomy. Three-year postoperative radiographs demonstrated a lateralized acetabulum with a horizontal roof and healing of the fatigue fracture; however, the craniomedial joint space remained narrow (Fig. 7B). At that time the patient reported pain only after strenuous activities with marked improvement in ROM and femoroacetabular clearance. A 16-year old male had bilateral protrusio acetabuli and coxa vara with right-sided medial joint space narrowing and marked restriction of motion. The patient complained of only occasional pain but desired
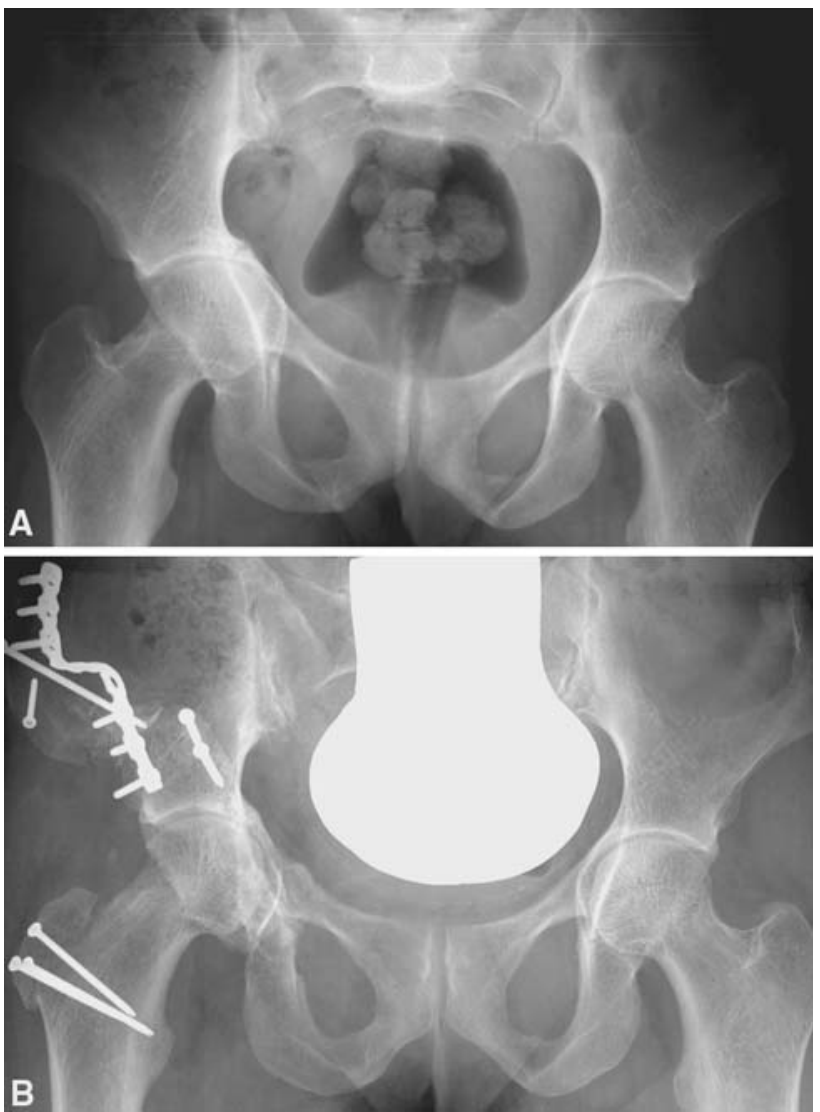

Fig. 7A-B (A) Bilateral protrusio acetabuli in a 25-year old female patient with an underlying diagnosis of osteogenesis imperfecta with complaints of limited ROM until a fatigue fracture of the acetabular fossa. MR arthrography revealed mild cartilage injury around the medial contour of the head. (B) Three-year postoperative radiographs demonstrated a lateralized acetabulum with a horizontal roof and healing of the fatigue fracture; however, the craniomedial joint space remained narrow.

improvement of his limited ROM. We therefore planned a staged joint preserving surgery for the right hip followed by the left hip in 6 months. The preoperative radiographs demonstrated a pincer acetabulum with a horizontal roof, and therefore, an acetabular reorientation would not address the underlying pathomorphology (Fig. 8A). We performed surgical dislocations with circumferential rim trimming with labral refixation and valgus intertrochanteric osteotomies to reduce the medializing forces. At two-year followup the right hip had a slight increase in medial joint space (Fig. $8 \mathrm{~B}$ ). The $30^{\circ}$ valgus osteotomy improved the joint clearance with markedly improved ROM.

\section{Discussion}

We describe the morphologic characteristics in hips with protrusio acetabuli with an acetabular line measuring $3 \mathrm{~mm}$ in males and $6 \mathrm{~mm}$ in females medial to the ilioischial line 

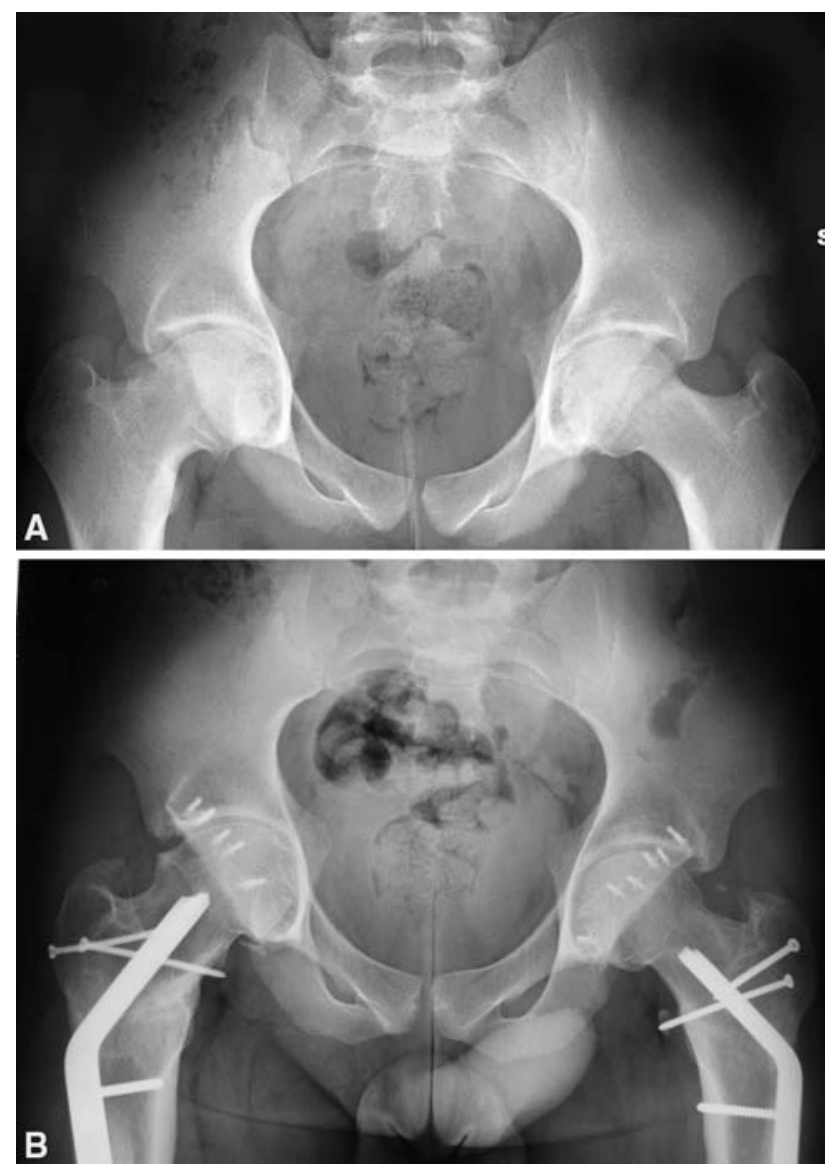

Fig. 8A-B (A) A radiograph of a 16-year old male with bilateral protrusio acetabuli and coxa vara with right-sided medial joint space narrowing is shown. The preoperative radiographs demonstrated a pincer acetabulum with a horizontal roof, and therefore, an acetabular reorientation would not address the underlying pathomorphology. (B) Radiographs at 2 years after surgery on the right side and 1.5 years on the left side demonstrated rim trimming with circumferential bone anchors after labral refixation. The right hip revealed a slight increase in medial joint space. The $30^{\circ}$ valgus osteotomy improved the joint clearance substantially resulting in markedly improved ROM.

$[1,2,7,13,19]$. In the protrusio acetabuli OA group, other parameters, especially the lateral center edge angle, the roof angle, and the extrusion index but also the topography of joint space narrowing, differed from those in the control OA group; however, such pathological values have not necessarily correlated with protrusion and may occur in a normal population [2]. Our observations suggest this constellation of abnormal radiographic measurements can be observed in protrusion even in the setting of advanced OA. The same abnormal radiographic measurements were observed in a younger group of protrusion hips but to a lesser degree; however, the absence of osteophytic reactions clearly illustrated important morphological particularities such as an excessively negative roof angle combined with an acetabular fossa extending high into the weight-bearing zone. These unique findings have never been reported in a case series, and the only other study reported on a single case by Dunlop and colleagues [7].

There are a number of limitations in the present study. We retrospectively identified patients from our protrusion database rather than from a prospective cohort comparison. Due to the rarity of the condition, a prospective study of protrusion acetabuli patients would not be practical due to expense and long study period. The OA control group was obtained from the hip arthroplasty database using age, gender, and Tönnis scale matched to the OA protrusion group, and the investigators attempted to create a cohort that would allow a comparison of the hip morphology of these two groups. Other morphologic characteristics (i.e., crossover sign) were not considered in the selection criteria for the OA control group, and therefore may be limit the comparison to protrusio OA group. The study did not utilize a validated, hip-specific outcome instrument and range of motion data to describe the functional outcome of the protrusion joint preservation patients. There were a limited number of patients with early- to midterm followup. Given the infrequent presentation of a young patient with protrusion acetabuli, the present series was the largest series of patients undergoing joint preservation surgery for acetabuli protrusion.

When joint-preserving surgery is being considered, abnormal acetabular morphology requires a more individual approach (Fig. 9). A careful individual and family history should be obtained, and the etiology should be determined with appropriate medical consultation. Complete physical examination including the hip range of motion, strength, and anterior and posterior impingement testing should be performed as well as an exam of the contralateral extremity. A plain radiograph with an adequate AP view provides the diagnosis. Further evaluation of protrusion candidates for joint-preserving surgery revealed the false profile radiographic view [15] was a very specific view to exclude hips with excessive posterior cartilage destruction in an otherwise minimally affected joint. The false profile projection has been part of the routine radiographic evaluation for acetabular dysplasia, and Lequesne [14] has demonstrated its value in acetabular protrusion. However, the false profile view has not found wider acceptance for imaging acetabular abnormalities. MR arthrography in the early stage of degeneration revealed that protrusio hips have reactive changes along the acetabular rim and on the head-neck junction that have typically been observed in pincer impingement [3, 11]. Dynamic gadolinium MRI of cartilage may also be useful to evaluate the degree of cartilage degeneration, but these studies may not be available at most institutions. Together with intraoperative findings of surgical hip dislocation in protrusion hips, we propose that that chronic impingement, especially its contre coup destruction of the cartilage in the 
Fig. 9 The treatment algorithm for protrusio joint preservation surgery is shown. We used MRA with radial sequences to determine the status of the articular cartilage. In cases without cartilage degeneration, open surgical dislocation with osteochondroplasty of the acetabular rim and femoral neck is recommended. Valgus ITO may be indicated in cases with inadequate femoroacetabular clearance. In cases with early cartilage degeneration on MRA, the osteochondroplasty is not sufficient and osteotomy of the pelvis, femur, or both depends on the individual morphology. MRA, magnetic resonance arthrography; ITO, intertrochanteric osteotomy; FA, femoroacetabular; WB, weight bearing.

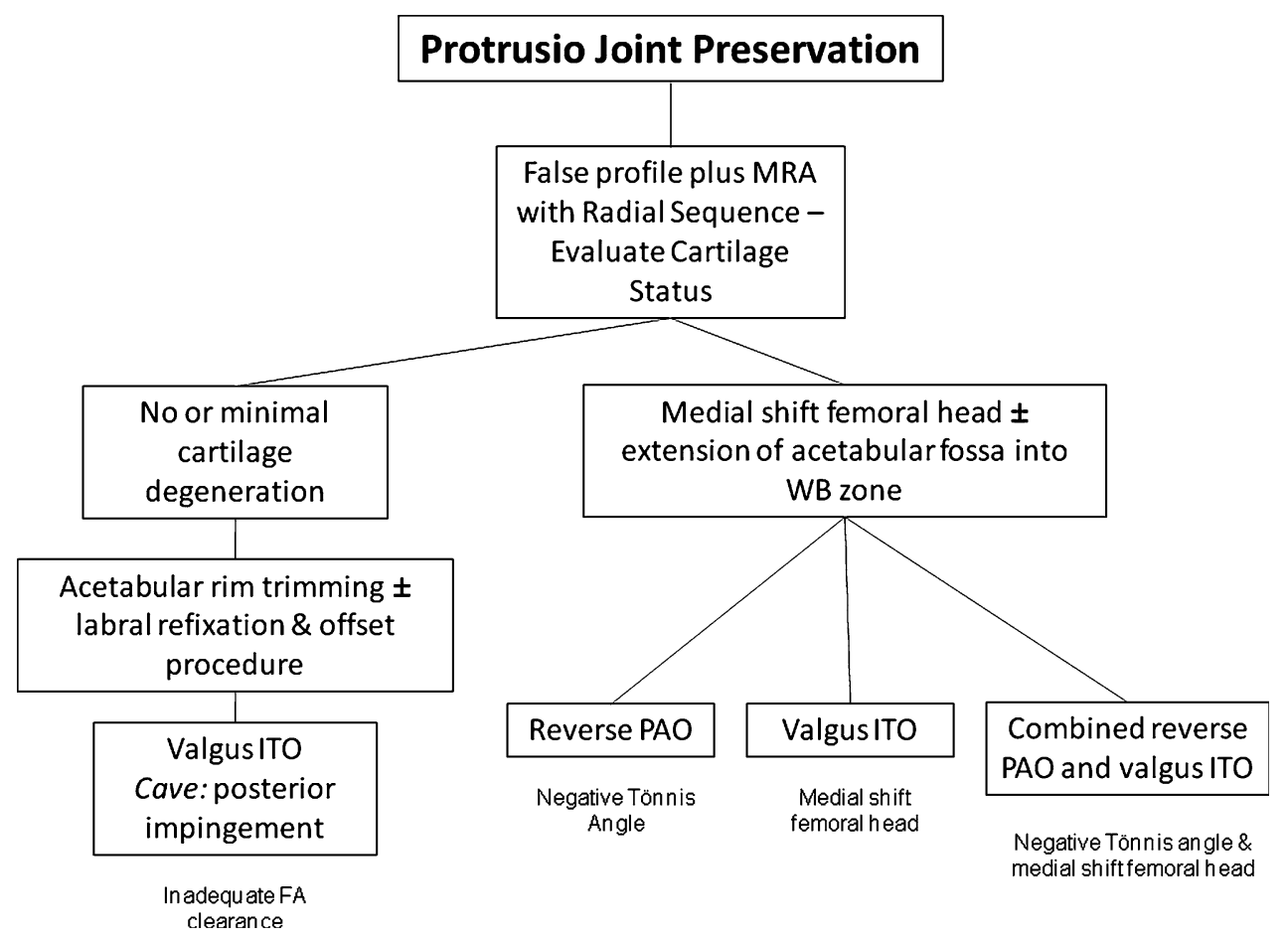

posterior joint, initiates the osteoarthritic process of the protrusio hip rather than the pathologic medializing forces as discussed in the literature [7, 18, 19, 22]. The precise amount of posterior cartilage injury is not known, but additional prospective studies will attempt to determine the effect of cartilage destruction on the clinical outcome.

We recommend the majority of cases begin the procedure with a surgical dislocation of the femoral head [9]. Open surgical dislocation will reduce the depth of the acetabulum by trimming of the acetabular rim, and labral refixation may be performed when appropriate [8]. Some cases may require osteochondroplasty of the head-neck junction and relative lengthening of the femoral neck in order to increase the femoroacetabular clearance [10]. In these cases, a valgus intertrochanteric osteotomy is indicated to lateralize the femoral head relative to the acetabulum.

When the MR arthrogram demonstrates an abnormality of the articular cartilage with extension of the acetabular fossa in the weight-bearing zone, trimming of the rim may be too late. Osteochondroplasty of the acetabular rim has rarely been sufficient for the treatment of the complex pathomorphology of an individual case. According to the given morphology, a femoral-sided osteotomy (ie, valgus intertrochanteric osteotomy) or a pelvis-sided osteotomy (ie, reversed periacetabular osteotomy [11]) may be appropriately performed simultaneously. However, the reversed periacetabular osteotomy for protrusion has been clearly more demanding than the classic periacetabular osteotomy for the dysplastic acetabulum [16]. In reverse
PAO, manipulation of the fragment for reversed PAO is more difficult because the abduction correction should be executed around the center of the femoral head. Long-term followup is necessary and may provide further information on the efficacy of the procedure to maintain hip function and, perhaps, delay the degenerative process.

Acknowledgments We thank Thomas Guggi from the Schulthess Clinic for his help assessing the protrusio data bank.

\section{References}

1. Alexander C. The aetiology of primary protrusio acetabuli. $\mathrm{Br} J$ Radiol. 1965;38:567-580.

2. Armbuster TG, Guerra J, Jr., Resnick D, Goergen TG, Feingold ML, Niwayama G, Danzig LA. The adult hip: an anatomic study. Part I: the bony landmarks. Radiology. 1978;128:1-10.

3. Beck M, Kalhor M, Leunig M, Ganz R. Hip morphology influences the pattern of damage to the acetabular cartilage: femoroacetabular impingement as a cause of early osteoarthritis of the hip. J Bone Joint Surg Br. 2005;87:1012-1018.

4. Crichton D, Curlewis C. Bilateral protrusio acetabuli (Otto pelvis). J Obstet Gynaecol Br Emp. 1962;69:47-51.

5. Crowninshield RD, Brand RA, Pedersen DR. A stress analysis of acetabular reconstruction in protrusio acetabuli. J Bone Joint Surg Am. 1983;65:495-499.

6. D'Arcy K, Ansell BM, Bywaters EG. A family with primary protrusio acetabuli. Annals Rheum Dis. 1978;37:53-57.

7. Dunlop CC, Jones CW, Maffulli N. Protrusio acetabuli. Bull Hosp Jt Dis. 2005;62:105-114.

8. Espinosa N, Beck M, Rothenfluh DA, Ganz R, Leunig M. Treatment of femoro-acetabular impingement: preliminary results of labral refixation. Surgical technique. J Bone Joint Surg Am. 2007;89 Suppl 2 Pt.1:36-53. 
9. Ganz R, Gill TJ, Gautier E, Ganz K, Krugel N, Berlemann U. Surgical dislocation of the adult hip a technique with full access to the femoral head and acetabulum without the risk of avascular necrosis. J Bone Joint Surg Br. 2001;83:1119-1124.

10. Ganz R, Huff TW, Leunig M. Extended retinacular soft-tissue flap for intraarticular hip surgery: Surgical technique, indications and results of its application. Instruc Course Lect. 2009;58:241255.

11. Ganz R, Parvizi J, Beck M, Leunig M, Notzli H, Siebenrock KA. Femoroacetabular impingement: a cause for osteoarthritis of the hip. Clin Orthop Relat Res. 2003;417:112-120.

12. Gilmour J. Adolescent deformities of the acetabulum: an investigation into the nature of protrusio acetabuli. Brit J Surg. 1939;26:670-699.

13. Kindynis P, Garcia J. Protrusio acetabuli. An update on the primary and secondary acetabular protrusion [in French]. J Radiol. 1990;71:415-424.

14. Lequesne M. Coxopathies chroniques de l'adult: diagnostique et traitment. Encycl Med Chir, Appareil Locom. 2000;14-308-A 10:1-21.

15. Lequesne MG, Laredo JD. The faux profil (oblique view) of the hip in the standing position. Contribution to the evaluation of osteoarthritis of the adult hip. Ann Rheum Dis. 1998;57:676-681.

16. Leunig M, Huff TW, Ganz R. Femoroacetabular impingement: treatment of the acetabular side. Instruc Course Lect. 2009;58: 223-229.

17. Locher S, Werlen S, Leunig M, Ganz R. MR-Arthrography with radial sequences for visualization of early hip pathology not visible on plain radiographs [in German]. Z Orthop Ihre Grenzgeb. 2002;140:52-57.

18. Maquet P. Biomechanics of the Hip. Berlin, Germany: Springer Verlag; 1985.

19. McBride MT, Muldoon MP, Santore RF, Trousdale RT, Wenger DR. Protrusio acetabuli: diagnosis and treatment. J Am Acad Orthop Surg. 2001;9:79-88.

20. Otto AW. Ein Becken, mit kugelformig augedehnten Pfannen. In: Heft E, ed. Seltene Beobachtungen zur Anatomie, Physiologie und Pathologie gehorig. Vol IX. Breslau: Verlag Willibald August Holaufer; 1816:19-20.
21. Overgaard K. Otto's disease and other forms of protrusio acetauli. Acta Radiologica. 1935;16:390-419.

22. Pauwels F, Furlong RJ, Maquet P. Biomechanics of the Normal and Diseased Hip: Theoretical Foundation, Technique and Results of Treatment-An Atlas. Berlin, Germany: Springer Verlag; 1976.

23. Reynolds D, Lucas J, Klaue K. Retroversion of the acetabulum. A cause of hip pain. J Bone Joint Surg Br. 1999;81:281-288.

24. Rosenmeyer B, Viernstein K, Schuhmann HJ. Mittelfristige ergebnisse der valgisierenden und medialisierenden intertrochanteren osteotomie mit verkurzung des coxalen femurendes bei der primaren protrusio acetabuli. Arch Orthop Unfall Chir. 1973;77:138-148.

25. Sharp IK. Acetabular dysplasia (The acetabular angle). J Bone Joint Surg Br. 1961;43:268-272.

26. Siebenrock KA, Kalbermatten DF, Ganz R. Effect of pelvic tilt on acetabular retroversion: a study of pelves from cadavers. Clin Orthop Relat Res. 2003;407:241-248.

27. Siebenrock KA, Schoeniger R, Ganz R. Anterior femoroacetabular impingement due to acetabular retroversion. Treatment with periacetabular osteotomy. J Bone Joint Surg Am. 2003;85:278-286.

28. Smith-Petersen MN. Treatment of malum coxae senilis, old slipped upper femoral, intrapelvic protrusion of the acetabulum, and coxa plana by means of acetabuloplasty. J Bone Joint Surg Am. 1936;18:869-880.

29. Steel HH. Protrusio acetabuli: its occurrence in the completely expressed Marfan syndrome and its musculoskeletal component and a procedure to arrest the course of protrusion in the growing pelvis. J Pediat Orthop. 1996;16:704-718.

30. Tönnis D, Heinecke A. Acetabular and femoral anteversion: relationship with osteoarthritis of the hip. J Bone Joint Surg Am. 1999;81:1747-1770.

31. Van de Velde S, Fillman R, Yandow S. Protrusio acetabuli in Marfan syndrome: indication for surgery in skeletally immature Marfan patients. J Pediat Orthop. 2005;25:603-606.

32. Wenger DE, Kendell KR, Miner MR, Trousdale RT. Acetabular labral tears rarely occur in the absence of bony abnormalities. Clin Orthop Relat Res. 2004;26:145-150. 